\section{(2) OPEN ACCESS}

\title{
Medical and neurobehavioural phenotypes in carriers of X-linked ichthyosis-associated genetic deletions in the UK Biobank
}

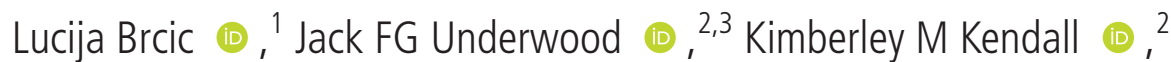 \\ Xavier Caseras (1), ${ }^{2}$ George Kirov (10, ${ }^{2}$ William Davies (1) ${ }^{1,2,3}$
}

\begin{abstract}
- Additional material is published online only. To view, please visit the journal online (http://dx.doi.org/10.1136/ jmedgenet-2019-106676)

${ }^{1}$ School of Psychology, Cardiff University, Cardiff, UK ${ }^{2}$ MRC Centre for Neuropsychiatric Genetics and Genomics and Division of Psychological Medicine and Clinical Neurosciences, School of Medicine, Cardiff University, Cardiff, UK

${ }^{3}$ Neuroscience and Mental Health Research Institute, Cardiff University, Cardiff, UK
\end{abstract}

Correspondence to Dr William Davies, School of Psychology, Tower Building, 70 Park Place, Cardiff University, Cardiff, CF10 3AT, UK; daviesw4@cardiff.ac.uk

Received 5 November 2019 Revised 20 December 2019 Accepted 23 January 2020 Published Online First 5 March 2020

Check for updates

(c) Author(s) (or their employer(s)) 2020. Re-use permitted under CC BY. Published by BMJ.

To cite: $B r c i c ~ L$,

Underwood JFG, Kendall KM,

et al. J Med Genet

2020:57:692-698.

\section{ABSTRACT}

Background X-linked ichthyosis (XLI) is an uncommon dermatological condition resulting from a deficiency of the enzyme steroid sulfatase (STS), often caused by X-linked deletions spanning STS. Some medical comorbidities have been identified in XLI cases, but small samples of relatively young patients has limited this. STS is highly expressed in subcortical brain structures, and males with XLI and female deletion carriers appear at increased risk of developmental/mood disorders and associated traits; the neurocognitive basis of these findings has not been examined.

Methods Using the UK Biobank resource, comprising participants aged 40-69years recruited from the general UK population, we compared multiple medical/ neurobehavioural phenotypes in males $(n=86)$ and females $(n=312)$ carrying genetic deletions spanning STS $(0.8-2.5 \mathrm{Mb})$ (cases) to male $(n=190577)$ and female $(n=227862)$ non-carrier controls.

Results We identified an elevated rate of atrial fibrillation/flutter in male deletion carriers $(10.5 \%$ vs $2.7 \%$ in male controls, Benjamini-Hochberg corrected $p=0.009)$, and increased rates of mental distress $(p=0.003)$, irritability $(p<0.001)$ and depressive-anxiety traits $(p<0.05)$ in male deletion carriers relative to male controls completing the Mental Health Questionnaire. While academic attainment was unaffected, male and female deletion carriers exhibited impaired performance on the Fluid Intelligence Test (Cohen's $d \leq 0.05$, corrected $p<0.1)$. Neuroanatomical analysis in female deletion carriers indicated reduced right putamen and left nucleus accumbens volumes (Cohen's $d \leq 0.26$, corrected $p<0.1$ ).

Conclusion Adult males with XLI disease-causing deletions are apparently at increased risk of cardiac arrhythmias and self-reported mood problems; altered basal ganglia structure may underlie altered function and XLI-associated psychiatric/behavioural phenotypes. These results provide information for genetic counselling of deletion-carrying individuals and reinforce the need for multidisciplinary medical care.

\section{INTRODUCTION}

X-linked ichthyosis (XLI (OMIM: 308100)) is an uncommon dermatological condition characterised by the presence of large dark-brown scales, ${ }^{1}$ although much milder skin phenotypes have been reported ${ }^{2}$; it occurs due to deficiency of the enzyme steroid sulfatase (STS), encoded by the X-linked STS gene (OMIM: 300747). STS cleaves sulfate groups from steroid hormones (eg, dehydroepiandrosterone sulfate (DHEAS)) altering their solubility/activity; the XLI-associated skin phenotype arises from cholesterol sulfate accumulation in the stratum corneum. $80-90 \%$ of XLI cases are caused by complete/partial deletion of STS, with remaining cases attributable to STS point mutation(s); the typical deletion $(\sim 1.5 \mathrm{Mb})$ encompasses STS and a small number of adjacent genes. ${ }^{3}$ In $\sim 85 \%$ of cases, the mutation is transmitted from unaffected (or mildly affected) carrier mothers, and in the remainder it occurs de novo during parental gametogenesis. $^{4}$

Several extracutaneous comorbidities have been reported in individuals possessing XLIassociated mutations: a) benign corneal opacities affect $\sim 10 \%-50 \%$ of males with XLI and $\sim 25 \%$ of female carriers, ${ }^{1}$ b) $\sim 20 \%$ of males with XLI have cryptorchidism; an associated risk of testicular germ cell cancer is less clear and supported by a few case reports ${ }^{15}$ and c) delayed/prolonged labour affects $\sim 60 \%$ of female carriers. ${ }^{16}$ Occasional comorbidities include: pyloric hypertrophy, congenital defect of the abdominal wall, acute lymphoblastic leukaemia, bilateral periventricular nodular heterotopia and end-stage renal failure. ${ }^{1}$ Rare, larger genetic deletions which can include NLGN4X and KAL are associated with a number of neurological conditions such as epilepsy, intellectual disability, autism and anosmia, and contiguous gene syndromes including Rud, Conradi and Kallman syndromes. ${ }^{13}$ To date, samples of patients with XLI and carrier females have been relatively small/superficially phenotyped, and larger-scale studies may reveal hitherto unappreciated comorbidities with implications for morbidity/mortality.

STS is expressed in the developing and adult human brain (with highest expression in subcortical structures ${ }^{78}$ ) and may therefore influence neurodevelopment. Boys with XLI are at elevated risk of developing attention deficit hyperactivity disorder (ADHD) and motor problems, ${ }^{3910}$ and also potentially early onset psychosis. ${ }^{11}$ We have previously shown that males with XLI exhibit higher rates of inattention, impulsivity (but not motor impulsivity), mood problems, disruptive behaviour and autismrelated traits, and are more likely to be diagnosed with developmental conditions (including ADHD/ autism) and mood disorders, when compared with males from the general population. ${ }^{12}$ A study of 
female carriers revealed a comparable suite of behavioural differences from control subjects, together with an increased likelihood of postpartum depression. ${ }^{6}$ The pattern of behavioural phenotypes seen in males with XLI/carrier females overlaps with that seen in STS-deficient mice, ${ }^{13-17}$ and may therefore be largely ascribed to biological effects of STS deficiency rather than ascertainment or socialisation effects. Previous behavioural phenotyping approaches in XLI have been suboptimal: a) survey-based studies did not collect genetic data and so could not objectively confirm or define STS deletion carrier status, and these studies may theoretically have elicited responses from more severely affected individuals inflating risk estimates, b) only relatively early age points have been assessed (average age $<45$ years) and c) studies have had either no control group, or no contemporaneously recruited control group. No study has yet investigated the cognitive or neurobiological basis of behavioural phenotypes in XLI. To address these limitations/knowledge gaps, here we use the power of the UK Biobank, a large, accessible resource comprising extensively phenotyped and genotyped members of the population of the UK, ${ }^{18}$ to compare medical/medication history, objective/self-reported behavioural/mental health measures, cognition and subcortical neuroanatomy between males and females carrying deletions most commonly seen in XLI and sex-matched non-carrier controls.

\section{METHODS}

\section{Participants}

Participants were individuals (aged 40-69 years) recruited under UK Biobank informed consent procedures between 2006-2010, for which anonymised genotype/phenotype data were available. ${ }^{19}$

\section{CNV calling}

Anonymised genotype data were downloaded as raw (CEL) files from the UK Biobank website, ${ }^{19}$ stored on a secure Linux server and analysed with UNIX-based commands. Affymetrix Power Tools (APT) software ${ }^{20}$ was used to generate normalised signal intensity data, genotype calls and confidences. This argument incorporated genotypic sex data downloaded from the UK Biobank website, and compared with sex data generated through PennCNV-Affy software. ${ }^{21}$ Approximately 750000 biallelic markers were analysed through PennCNV-Affy to process cluster plots. Canonical genotype clusters, Log $\mathrm{R}$ ratios and $\mathrm{B}$ allele frequencies were generated to complete the PennCNV recommended process for $\mathrm{CNV}$ calls. Individuals with deletions of $0.8-2.5 \mathrm{Mb}$ spanning STS were identified, with calls and coordinates based on the GRCh37/hg19 genome build; this range was selected to reflect the majority of XLI cases, to facilitate robust $\mathrm{CNV}$ calling, and to exclude individuals with multiple complex medical issues arising from large contiguous gene deletions. Following QC, CNV data were available for a total of 418837 individuals.

\section{Measures}

Hospital diagnoses according to the International Statistical Classification of Diseases and Related Health Problems Revision-10 (ICD-10), ${ }^{22}$ self-reported non-cancer illnesses, relevant questions from the Mental Health Questionnaire (MHQ) ${ }^{23}$ and medication history were analysed. Highest levels of academic qualification and key performance measures on seven cognitive tasks (transformed and converted to z-scores as described previously ${ }^{24}$ ) were also analysed: number of incorrect matches on the Pairs Matching Test (episodic memory), mean time to correctly identify matches in the Reaction Time Task (simple processing speed), total number of correct answers in the 13-question Fluid Intelligence Test (reasoning/problem-solving), ${ }^{25}$ maximum number of digits remembered in the 'Digit Span' task (numeric working memory), number of correct substitutions in a Symbol Digit Substitution Test (complex processing speed) and time to complete two variants of the Trail Making Task (visual attention). Brain images were acquired using Siemens Skyra 3T scanners in UK Biobank's imaging centres in Cheadle and Newcastle, UK using identical acquisition protocols ${ }^{26}$; T1-weighted brain images were processed using automated methods implemented in FreeSurfer ${ }^{27}$ to obtain volumetric estimates for eight right and left subcortical regions.

\section{Statistics}

Data were analysed using SPSS V.25.0 (IBM). As male and female deletion phenotypes could differ in magnitude and/or nature, two comparisons were performed: male deletion carriers versus male non-carriers, and female deletion carriers versus female non-carriers. Across the overall sample for each cognitive/neuroimaging measure, outlying values $>2.2$ times the IQR below the first quartile, or above the third quartile, were excluded. ${ }^{28}$ Categorical data were analysed using $\chi^{2}$ test (continuity-adjusted for $2 \times 2$ analyses)/Fisher's exact test, with ORs and $95 \%$ CIs presented as a measure of effect size. Normally distributed data were compared using unpaired t-test. Ordinal/non-normally distributed data, and small datasets ( $<30$ participants), were compared using Mann-Whitney U test, with Cohen's d presented as a measure of effect size. ${ }^{29}$ For cognitive analyses with sample sizes $>30$, hierarchical linear regression controlling for age was performed. ${ }^{24}$ Data are presented as median values (with 95\% $\mathrm{CIs}$ ) or mean $\pm \mathrm{SE}$ of the mean. Two-sided $\mathrm{p}$ values $<0.05$ were regarded as nominally significant, with $p$ values $<0.1$ after Benjamini-Hochberg adjustment ${ }^{30}$ regarded as surviving correction for multiple comparisons.

\section{RESULTS}

\section{Identification and characterisation of deletion cases}

We identified 86 male and 312 female deletion carriers, and 190577 male and 227862 female non-carriers, giving deletion rates of $\sim 1 / 2200$ in males and $\sim 1 / 730$ in females. The mean deletion size was $1.60 \pm 0.01 \mathrm{Mb}$ from ChrX:6 487 716-8 087815 , encompassing the PUDP/HDHD1 (OMIM: 306480), STS, VCX (OMIM: 300229) and PNPLA4 (OMIM: 300102) genes and the MIR4767 microRNA. Male deletion subjects did not differ significantly from male controls in terms of age $(58.0 \pm 0.8$ vs $57.1 \pm 0.02$ years, respectively, $t[190606]=-0.999, p=0.318)$; the ages of female deletion subjects and female controls were also equivalent $(56.3 \pm 0.5$ vs $56.7 \pm 0.02$ years, respectively, $\mathrm{t}[228024]=0.736, \mathrm{p}=0.461)$.

\section{ICD-10 diagnoses}

Nine ICD-10 unique descriptive codes were present in $>2500$ males overall and $>2.5 \%$ of male deletion subjects, of which two were significantly more common in male deletion carriers than in control males (online supplementary table 1): 'atrial fibrillation/flutter' $(10.5 \%$ vs $2.7 \%$, OR 4.2 (95\% CI 2.1 to $8.3), p=0.001)$ and 'skin of other and unspecified parts of face' $(5.8 \%$ vs $1.5 \%$, OR 4.0 (95\% CI 1.6 to 9.9), $\mathrm{p}=0.01)$; while these $\mathrm{p}$ values would not survive stringent multiple comparison testing taking into account all possible ICD-10 codes, they did survive multiple comparison testing across the nine aforementioned codes (corrected $\mathrm{p}=0.009$ and 0.045 , respectively). Ten ICD-10 unique descriptive codes were present in $>2500$ 
females overall and $>2.5 \%$ of female deletion subjects, none of which were significantly more common in deletion than control subjects (online supplementary table 2). Diagnosis rates of developmental and mood/anxiety disorders did not differ between male and female deletion and control subjects, although baseline rates of each were very low across groups $(<0.5 \%)$ (online supplementary tables 3 and 4).

\section{Self-reported non-cancer illnesses}

We compared rates of self-reported non-cancer physical/mental illnesses of interest based on the ICD-10 findings above, or previous literature, across groups (online supplementary tables 5 and 6). Compared with male controls, male deletion cases reported a significantly higher prevalence of blistering/desquamating skin disorder (4.7\% vs $0.2 \%$, OR 28.6 (95\% CI 10.4 to $78.4)$, corrected $\mathrm{p}<0.020)$ and allergy/hypersensitivity/anaphylaxis $(4.7 \%$ vs $0.5 \%$, OR 9.1 (95\% CI 3.3 to 24.9 ), corrected $\mathrm{p}=0.020)$, and a nominally significantly increased rate of heart arrhythmia (3.5\% vs $0.6 \%$, OR 5.9 (95\% CI 1.9 to 18.6$)$, $\mathrm{p}=0.016)$, atrial flutter $(1.2 \%$ vs $0.0 \%$, OR 31.1 (95\% CI 4.3 to 226.6$), \mathrm{p}=0.032)$ and eczema/dermatitis $(7.0 \%$ vs $2.7 \%$, OR 2.7 (95\% CI 1.2 to 6.2 ), $\mathrm{p}=0.028$ ). Two conditions related to those previously reported in males with XLI were not reported significantly more frequently in male deletion carriers than male controls: 'undescended testicle' $(0.0 \%$ vs $0.1 \%, \mathrm{p}>0.99)$ and 'cataract' (3.5\% vs $1.6 \%$, OR 2.3 (95\% CI 0.7 to 7.2$), \mathrm{p}=0.15)$. No non-cancer illnesses we assessed were reported significantly more frequently in female deletion than female control subjects.

\section{Mental Health Questionnaire}

Twenty-one male deletion and 95 female deletion carriers completed the MHQ, together with 58855 male controls and 76439 female controls. Male deletion carriers reported a significantly higher likelihood of having suffered mental distress preventing usual activities compared with male controls $(57 \%$ vs 26\%, OR 3.8 (95\% CI 1.6 to 9.0), $\mathrm{p}=0.003$ ), but not a greater likelihood of having sought or received help for mental distress; female deletion carriers did not differ significantly from female controls on these measures (table 1). Mental health diagnoses reported in at least one male or female deletion carrier did not differ in frequency between deletion carriers and controls (table 1). No male or female deletion carriers reported having been diagnosed with any of the following conditions: schizophrenia/other psychotic disorder, personality disorder, mania/ bipolar disorder, bulimia nervosa, psychological overeating/ binge eating, autism spectrum conditions, anorexia nervosa, agoraphobia or $\mathrm{ADHD}$, and none of these conditions differed in frequency between deletion carriers and control subjects $(\mathrm{p}>0.99)$.

Responses to the remaining questions of the MHQ are presented in online supplementary tables 7 and 8 . Male deletion carriers were more likely than male controls to have experienced 'recent easy annoyance or irritability' $(p<0.001)$ or to have 'ever experienced a period of extreme irritability' $(p=0.031)$, and female deletion carriers were more likely than female controls to have experienced the former $(p=0.018)(d \leq 0.02)$. Male deletion carriers were significantly more likely than male controls to have experienced 'prolonged feelings of sadness or depression', 'prolonged loss of interest in normal activities' (OR 3.9 (95\% CI 1.4 to 10.6 ), $\mathrm{p}=0.009$ and OR 3.5 (95\% CI 1.5 to 8.6), $\mathrm{p}=0.006$, respectively) and 'recent restlessness' $(\mathrm{p}=0.008$, $\mathrm{d}=0.012$ ); we found weaker evidence for male deletion carriers being more affected than male controls by recent depressionrelated traits including: 'feelings of inadequacy' $(p=0.039)$, 'trouble concentrating on things' $(p=0.011)$, 'thoughts of suicide and self-harm' $(p=0.024)$ and 'lack of interest or pleasure in doing things' $(p=0.015)(d<0.015)$. There was a nominally significantly increased prevalence of some anxiety-related traits in male deletion carriers relative to male controls, notably 'ever feeling worried, tense or anxious for most of a month or longer' (OR 2.8 (95\% CI 1.2 to 6.7), p=0.027). Male deletion carriers did not differ from male controls with respect to traumatic event exposure, unusual/psychotic experiences, most aspects of alcohol use, cannabis use or happiness/well-being measures. Female deletion carriers differed from controls on some responses $(0.01<\mathrm{p}<0.05)$; notably, the former group were more likely to have experienced a period of mania/excitability (OR 2.5 (95\% CI 1.2 to 5.1), $\mathrm{p}=0.02$ ). Interestingly, both male and female deletion carriers reported consuming less alcohol than controls on a typical drinking day $(p=0.013$ and $p=0.033$, respectively, $\mathrm{d} \leq 0.02)$.

\section{Medications}

We found no difference in prescription rates for medications commonly used to treat heart arrhythmias (listed in online supplementary table 9) between male deletion carriers and male controls: male deletion $(6 / 86,7.0 \%)$ versus male controls $(16590 / 190577,8.7 \%)\left(\chi_{[1]}^{2}=0.142, p=0.706\right)$. Nor did we

\begin{tabular}{|c|c|c|c|c|c|c|}
\hline Measure & Male control & Male deletion & $\begin{array}{l}\text { Statistical } \\
\text { analysis }\end{array}$ & Female control & $\begin{array}{l}\text { Female } \\
\text { deletion }\end{array}$ & $\begin{array}{l}\text { Statistical } \\
\text { analysis }\end{array}$ \\
\hline $\begin{array}{l}\text { Ever suffered mental distress preventing usual } \\
\text { activities? (Yes/No) }\end{array}$ & $15068(26 \%) / 42882(74 \%)$ & $12(57 \%) / 9(43 \%)$ & $\begin{array}{l}\chi_{[1]}^{2}=9.02 \\
p=0.003\end{array}$ & $29250 / 46323$ & $30 / 63$ & $\begin{array}{l}\chi_{[1]}^{2}=1.37 \\
p=0.242\end{array}$ \\
\hline $\begin{array}{l}\text { Ever sought or received help for mental distress? } \\
\text { (Yes/No) }\end{array}$ & $17522 / 41137$ & $7 / 14$ & $\begin{array}{l}\chi_{[11}^{2}=0.01 \\
p=0.914\end{array}$ & $35122 / 41035$ & $39 / 56$ & $\begin{array}{l}\chi_{[11}^{2}=0.786, \\
p=0.375\end{array}$ \\
\hline Social anxiety or social phobia (Yes/No) & 756/58 099 & $0 / 21$ & $P>0.99$ & $892 / 75547$ & $1 / 94$ & $P>0.99$ \\
\hline Phobia (other than social or agoraphobia) (Yes/No) & $576 / 58279$ & $1 / 20$ & $P=0.187$ & $1256 / 75183$ & 2/93 & $\mathrm{P}=0.671$ \\
\hline Panic attacks (Yes/No) & $2266 / 56589$ & $1 / 20$ & $\mathrm{P}=0.562$ & $5197 / 71242$ & $6 / 89$ & $\begin{array}{l}\chi_{[11}^{2}=0.000, \\
p>0.99\end{array}$ \\
\hline Obsessive compulsive disorder (Yes/No) & $329 / 58526$ & $1 / 20$ & $\mathrm{P}=0.111$ & $508 / 75931$ & 0/95 & $P>0.99$ \\
\hline Depression (Yes/No) & $9188 / 49667$ & $6 / 15$ & $\mathrm{P}=0.125$ & $19587 / 56852$ & $24 / 71$ & $\begin{array}{l}\chi_{[11}^{2}=0.000 \\
p>0.99\end{array}$ \\
\hline $\begin{array}{l}\text { Anxiety, nerves or generalised anxiety disorder (Yes/ } \\
\text { No) }\end{array}$ & $6287 / 52568$ & $3 / 18$ & $\mathrm{P}=0.486$ & $12889 / 63550$ & $16 / 79$ & $\begin{array}{l}\chi_{[1]}^{2}=0.000, \\
p>0.99\end{array}$ \\
\hline
\end{tabular}


Table 2 Highest academic qualification achieved by male and female deletion carriers and controls

\begin{tabular}{|c|c|c|c|c|c|c|}
\hline Highest academic qualification & $\begin{array}{l}\text { Male control } \\
(n=180071)\end{array}$ & $\begin{array}{l}\text { Male deletion } \\
(n=78)\end{array}$ & Statistical analysis & $\begin{array}{l}\text { Female control } \\
(\mathrm{n}=212817)\end{array}$ & $\begin{array}{l}\text { Female } \\
\text { deletion } \\
(n=290)\end{array}$ & Statistical analysis \\
\hline College/University degree & $62371(35 \%)$ & $18(23 \%)$ & \multirow[t]{6}{*}{$P=0.083$} & $67798(32 \%)$ & $84(29 \%)$ & \multirow{6}{*}{$\chi_{[5]}^{2}=3.995, p=0.550$} \\
\hline A/AS Levels & $19794(11 \%)$ & $13(17 \%)$ & & $27229(13 \%)$ & $37(13 \%)$ & \\
\hline O Levels/GCSEs & $36430(20 \%)$ & $21(27 \%)$ & & $55181(26 \%)$ & 75 (26\%) & \\
\hline CSES & $10424(6 \%)$ & $2(2 \%)$ & & $12550(6 \%)$ & $24(8 \%)$ & \\
\hline NVQ/HND/HNC & $17684(10 \%)$ & $6(8 \%)$ & & $10100(4 \%)$ & $12(4 \%)$ & \\
\hline None & $33368(18 \%)$ & $18(23 \%)$ & & $39959(19 \%)$ & $58(20 \%)$ & \\
\hline
\end{tabular}

find any evidence for differential prescription of medications commonly used to treat ADHD-related symptoms (online supplementary table 9$)$ : male deletion $(0 / 86,0 \%)$ versus male controls $(14 / 190577,0 \%)(p>0.99)$ and female deletion $(0 / 312$, $0 \%)$ versus female controls $(11 / 227862,0 \%)(\mathrm{p}>0.99)$. Finally, we found no evidence that prescription rates of medications used to treat mood symptoms (online supplementary table 9) differed across groups: male deletion $(5 / 86,5.8 \%)$ versus male controls $(9419 / 190577,4.9 \%)(\mathrm{p}=0.617)$ and female deletion $(31 / 312,9.9 \%)$ versus female controls (21 008/227 862, 9.2\%) $\left(\chi_{[1]}^{2}=0.115, \mathrm{p}=0.735\right)$.

\section{Academic qualifications and cognitive function}

Neither male deletion, nor female deletion, carriers differed from their respective controls with respect to highest academic qualification achieved (table 2). Male deletion subjects (57.5 \pm 0.8 years) and female deletion subjects ( $56.3 \pm 0.45$ years) were compared with a subset of closely age-matched male (55-60 years, mean: 57.7 \pm 0.01 years) and female (55-60years, mean: $57.7 \pm 0.01$ years) control subjects on the cognitive tests. On average, male deletion carriers performed more poorly than male controls across all tasks, exhibiting significantly slower reaction times in the Reaction Time Test $(B=0.217 \pm 0.101, \beta=0.010$, $\mathrm{p}=0.032$ ), and providing significantly fewer correct answers in the Fluid Intelligence Test $(B=-0.465 \pm 0.190, \beta=-0.021$, $\mathrm{p}=0.014)$; however, only the latter difference reached significance after correcting for multiple testing (corrected $\mathrm{p}=0.098$ ) (table 3 ). Female deletion carriers only demonstrated significantly different (worse) performance from female controls on the Fluid Intelligence Test (corrected $\mathrm{p}<0.0063, \mathrm{~d}=0.054$ ) (table 3 ).

Table 3 Performance on key measures of seven cognitive tasks by male and female deletion carriers and controls

\begin{tabular}{|c|c|c|c|c|}
\hline Cognitive task & Control group & Deletion group & Statistical comparison & $\begin{array}{l}\text { Benjamini- } \\
\text { Hochberg } \\
\text { corrected p } \\
\text { value }\end{array}$ \\
\hline \multicolumn{5}{|l|}{ Male participants } \\
\hline $\begin{array}{l}\text { Pairs Matching Test (total number of } \\
\text { errors) }\end{array}$ & $-0.11(-0.11$ to -0.11$)(n=42990)$ & $0.25(-0.11$ to 0.54$)(n=86)$ & $B=0.202 \pm 0.112, \beta=0.009, p=0.071$ & 0.166 \\
\hline Reaction Time Test & $-0.19(-0.19$ to -0.18$)(n=42626)$ & $-0.025(-0.19$ to 0.265$)(n=86)$ & $B=0.217 \pm 0.101, \beta=0.010, p=0.032$ & 0.112 \\
\hline $\begin{array}{l}\text { Fluid Intelligence Test (total number of } \\
\text { correct answers) }\end{array}$ & $0.40(-0.07$ to 0.40$)(n=13072)$ & $-0.07(-0.55$ to 0.40$)(n=31)$ & $\begin{array}{l}B=-0.465 \pm 0.190, \beta=-0.021 \\
p=0.014\end{array}$ & 0.098 \\
\hline $\begin{array}{l}\text { Digit Span Test (maximum number of } \\
\text { digits remembered) }\end{array}$ & $0.21(0.21$ to 0.21$)(n=4195)$ & $0.21(-0.165$ to 0.97$)(n=10)$ & $U=18543.5, p=0.512$ & 0.563 \\
\hline $\begin{array}{l}\text { Symbol Digit Substitution Test (number } \\
\text { of correct substitutions) }\end{array}$ & $0.05(0.05$ to 0.05$)(n=11664)$ & $-0.35(-0.838$ to 0.345$)(n=13)$ & $\mathrm{U}=63851, \mathrm{p}=0.323$ & 0.452 \\
\hline $\begin{array}{l}\text { Trail Making Test } \mathrm{A} \text { (time to } \\
\text { completion) }\end{array}$ & $-0.19(-0.22$ to -0.17$)(n=10580)$ & $-0.04(-0.43$ to 1.07$)(n=14)$ & $U=58547, p=0.175$ & 0.306 \\
\hline $\begin{array}{l}\text { Trail Making Test B (time to } \\
\text { completion) }\end{array}$ & $-0.11(-0.13$ to -0.10$)(n=10588)$ & $0.125(-0.53$ to 0.44$)(n=14)$ & $\mathrm{U}=67499, \mathrm{p}=0.563$ & 0.563 \\
\hline \multicolumn{5}{|l|}{ Female participants } \\
\hline $\begin{array}{l}\text { Pairs Matching Test (total number of } \\
\text { errors) }\end{array}$ & $-0.11(-0.11$ to -0.11$)(n=54151)$ & $0.25(-0.11$ to 0.25$)(n=312)$ & $B=0.105 \pm 0.057, \beta=0.008, p=0.067$ & 0.235 \\
\hline Reaction Time Test & 0.01 (0.01 to 0.01$)(n=53692)$ & $-0.10(-0.24$ to 0.0495$)(n=309)$ & $\begin{array}{l}B=-0.0202 \pm 0.052, \beta=-0.002 \\
p=0.697\end{array}$ & 0.835 \\
\hline $\begin{array}{l}\text { Fluid Intelligence Test (total number of } \\
\text { correct answers) }\end{array}$ & $\begin{array}{l}-0.07(-0.07 \text { to }-0.07)(n=16615) \\
\text { (mean: } 0.05 \pm 0.0074)\end{array}$ & $\begin{array}{l}-0.07(-0.55 \text { to }-0.07)(n=103) \\
\text { (mean: }-0.31 \pm 0.0972)\end{array}$ & $\begin{array}{l}B=-0.352 \pm 0.096, \beta=-0.028 \\
p<0.001\end{array}$ & $<0.0063$ \\
\hline $\begin{array}{l}\text { Digit Span Test (maximum number of } \\
\text { digits remembered) }\end{array}$ & $0.21(0.21$ to 0.21$)(n=5386)$ & $0.21(-0.54$ to 0.59$)(n=36)$ & $B=0.058 \pm 0.160, \beta=0.005, p=0.716$ & 0.835 \\
\hline $\begin{array}{l}\text { Symbol Digit Substitution Test (number } \\
\text { of correct substitutions) }\end{array}$ & $0.05(0.05$ to 0.05$)(n=15163)$ & $0.15(-0.25$ to 0.54$)(n=64)$ & $\begin{array}{l}B=-0.063 \pm 0.114, \beta=-0.004 \\
p=0.581\end{array}$ & 0.835 \\
\hline $\begin{array}{l}\text { Trail Making Test } \mathrm{A} \text { (time to } \\
\text { completion) }\end{array}$ & $-0.02(-0.04$ to 0.00$)(n=13179)$ & $0.015(-0.28$ to 0.29$)(n=58)$ & $B=0.020 \pm 0.126, \beta=0.001, p=0.875$ & 0.875 \\
\hline $\begin{array}{l}\text { Trail Making Test B (time to } \\
\text { completion) }\end{array}$ & $0.01(-0.01$ to 0.03$)(n=13206)$ & $0.08(-0.17$ to 0.385$)(n=58)$ & $B=0.123 \pm 0.121, \beta=0.009, p=0.307$ & 0.716 \\
\hline
\end{tabular}

Data are presented as median z-scores with $95 \%$ confidence limits. 
Table 4 Volumes of eight subcortical brain regions (right and left hemisphere) in male and female deletion carriers and controls

\begin{tabular}{|c|c|c|c|c|c|}
\hline Hemisphere & Subcortical region & $\begin{array}{l}\text { Volume in control } \\
\text { female subjects }\left(\mathrm{cm}^{3}\right) \\
(\mathrm{n}=415)\end{array}$ & $\begin{array}{l}\text { Volume in female } \\
\text { deletion subjects }\left(\mathrm{cm}^{3}\right) \\
(\mathrm{n}=14)\end{array}$ & $\begin{array}{l}\text { Statistical } \\
\text { comparison } \\
\text { Mann-Whitney U } \\
\text { value, } p \text { value }\end{array}$ & $\begin{array}{l}\text { Benjamini-Hochberg } \\
\text { corrected } \mathrm{p} \text { value }\end{array}$ \\
\hline \multirow[t]{8}{*}{ Left } & Lateral ventricle & 7.62 (7.08 to 8.06$)$ & 9.32 (7.50 to 11.18$)$ & $2038,0.059$ & 0.189 \\
\hline & Thalamus & 7.15 (7.05 to 7.25$)$ & 7.17 (6.19 to 7.53$)$ & $2582.5,0.480$ & 0.640 \\
\hline & Caudate & 3.20 (3.17 to 3.24 ) & 3.15 (2.91 to 3.21 ) & $2347,0.226$ & 0.452 \\
\hline & Putamen & 4.84 (4.78 to 4.90$)$ & 4.44 (3.82 to 4.99 ) & $1912,0.030$ & 0.120 \\
\hline & Pallidum & 1.23 (1.19 to 1.25$)$ & 1.15 (0.99 to 1.25$)$ & $2168.5,0.106$ & 0.283 \\
\hline & Hippocampus & 4.10 (4.05 to 4.15 ) & 4.08 (3.79 to 4.51$)$ & $2823,0.857$ & 0.914 \\
\hline & Amygdala & $1.48(1.45$ to 1.50$)$ & 1.47 (1.30 to 1.57$)$ & $2676.5,0.617$ & 0.705 \\
\hline & Nucleus accumbens & 0.52 (0.50 to 0.53 ) & 0.44 (0.40 to 0.49 ) & $1668,0.007$ & 0.072 \\
\hline \multirow[t]{8}{*}{ Right } & Lateral ventricle & 7.17 (6.83 to 7.64$)$ & 8.57 (7.48 to 10.58$)$ & $2257,0.159$ & 0.363 \\
\hline & Thalamus & 6.28 (6.25 to 6.35$)$ & 6.11 (5.83 to 6.70$)$ & $2537,0.420$ & 0.611 \\
\hline & Caudate & 3.30 (3.26 to 3.36 ) & 3.21 (3.04 to 3.44 ) & $2462,0.338$ & 0.541 \\
\hline & Putamen & 4.64 (4.58 to 4.71$)$ & 4.31 (3.88 to 4.63 ) & $1713,0.009$ & 0.072 \\
\hline & Pallidum & 1.40 (1.39 to 1.42$)$ & 1.31 (1.16 to 1.40$)$ & $1816.5,0.019$ & 0.101 \\
\hline & Hippocampus & 4.23 (4.20 to 4.27$)$ & 4.19 (3.97 to 4.60$)$ & $2903,0.997$ & 0.997 \\
\hline & Amygdala & 1.53 (1.51 to 1.55$)$ & 1.46 (1.37 to 1.76$)$ & $2635,0.554$ & 0.682 \\
\hline & Nucleus accumbens & 0.54 (0.53 to 0.55$)$ & $0.50(0.45$ to 0.60$)$ & $2460,0.329$ & 0.541 \\
\hline
\end{tabular}

Data are presented as median values with $95 \%$ confidence limits.

\section{Subcortical neuroanatomy}

Neuroimaging data were available for only two male deletion carriers hence analysis was limited to a comparison between female deletion carriers $(n=14)$ and a subset of female controls $(n=415)$ matched as closely as possible for handedness, scanning centre, age at scanning $(61.2 \pm 2.9$ vs $61.0 \pm 0.04$ years, respectively, $\mathrm{t}[4.0]=-0.060, \mathrm{p}=0.955), \quad$ and intracranial volume $\left(1396 \pm 39\right.$ vs $1399 \pm 4 \mathrm{~cm}^{3}$, respectively, t $[13.2]=0.074$, $\mathrm{p}=0.942$ ). Four subcortical brain regions were nominally significantly smaller in deletion than control subjects (left and right putamen, right pallidum and left nucleus accumbens); two of these comparisons (right putamen and left nucleus accumbens) survived correction for multiple testing (corrected $\mathrm{p}=0.072$, $\mathrm{d}=0.254$ and $\mathrm{d}=0.264$, respectively), while a third almost did (right pallidum, corrected $\mathrm{p}=0.101, \mathrm{~d}=0.232$ ) (table 4).

\section{DISCUSSION}

We aimed to refine and extend the list of medical and neurobehavioural phenotypes linked to XLI-associated genetic mutations using an approach arguably less prone to confounding than those undertaken previously. The prevalence of the mutation-of-interest in our sample was $\sim 1 / 730$ females, a figure consistent with published estimates of 1/750-1200 based on prenatal screening data and mutation transmission rates. ${ }^{61}$ The prevalence of the mutation among males in our sample was $\sim 1 / 2200$, a figure slightly lower than the $\sim 1 / 1500$ estimate arising from prenatal screening in North American populations. ${ }^{32} 33$ Although the lower prevalence in our sample could reflect geographical genetic differences, it more likely reflects an ascertainment bias whereby some males with XLI-associated genetic deletions are not recruited into the UK Biobank; this could be due, in part, to psychological characteristics of this group. ${ }^{34}$ Our experimental strategy meant that individuals with small deletions or point mutations within STS would have been included in the non-deletion carrier 'control' group; however, the inclusion of these rare individuals would have negligible effects on the overall group score, and would likely act to reduce the magnitude of between-group effects.

Unsurprisingly, the prevalence of relevant skin phenotypes based on ICD-10 and self-report diagnostic data was significantly higher in male deletion carriers relative to noncarriers. However, $<6 \%$ of male deletion carriers reported a relevant diagnosis, implying that older STS-deficient individuals are only rarely being diagnosed with XLI. This may be because the dermatological manifestations of the condition are frequently mild with only more severe and/or visible cases recognised, and some cases could have been misdiagnosed as eczema/dermatitis. ${ }^{35}$ Within male deletion subjects, we found no evidence for increased rates of phenotypes most closely related to those previously suggested to be elevated in individuals with XLI (testicular maldescent and cataracts); given reliable existing data on an association between XLI and cryptorchidism in paediatric patients, ${ }^{1}$ the lack of association with testicular maldescent observed currently may be explained by an unwillingness or inability of older participants to self-report this condition.

We identified one robust novel medical phenotype, atrial fibrillation/flutter, presenting more commonly in male deletion carriers $(10.5 \%)$ than in controls $(2.7 \%)$; importantly, the prevalence rate of atrial fibrillation/flutter in our controls is comparable with that observed in epidemiological studies across Europe and the USA (2\%-3\%). ${ }^{36}$ Possible mechanism(s) underlying the relationship between XLI-associated mutations and heart arrhythmia are manifold and might be investigated in experimentally tractable systems. It is noteworthy that XLI impacts on circulating DHEAS levels, ${ }^{37}$ which have repeatedly been linked to atrial fibrillation in older men, ${ }^{39-41}$ and that paroxysmal supraventricular tachycardia has been noted in a young boy with XLI. ${ }^{42}$ DHEAS may feasibly influence atrial fibrillation through conversion to biologically active androgens and oestrogens, via vascular remodelling, or through its anti-inflammatory action. ${ }^{40}$ It is also of interest that microarray analysis has implicated reduced triadin expression in STS-deficient mouse tissues ${ }^{43}$ as, in man, the absence of cardiac triadin is associated with increased risk of arrhythmia. ${ }^{44}$ Although prescription rates for medication used to treat heart arrhythmias did not differ across groups, this might be explained by the fact that these medications are used to treat other conditions.

We found no evidence that male or female deletion carriers differed from their respective controls in terms of rates of 
psychiatric/neurological diagnoses, and prescription rates for medications used to treat ADHD and mood disorders were equivalent across groups. However, these findings should be viewed in light of low levels of psychopathology within the UK Biobank sample, ${ }^{18}$ and in particular, the very low baseline rate of developmental disorder diagnoses. MHQ analysis revealed that both male and female deletion carrier groups were affected by higher rates of irritability than their respective controls, an observation in line with our previous findings, ${ }^{612}$ and with elevated levels of aggression in STS-deficient mice. ${ }^{16}{ }^{46}$ Male deletion carriers were more likely than male controls to report experiencing psychological distress and a variety of depressive and anxiety-related symptoms, and mood symptoms may be under-recognised within this group. The increased rate of depressive and anxiety-related traits in male deletion carriers is unlikely to be due to increased exposure to traumatic events, but may feasibly be related to having to live with a potentially stigmatising, lifelong skin condition; however, the fact that $S t s$-deficient mice exhibit anxiety-related traits ${ }^{16}$ suggests that biological influences contribute. Female deletion carriers showed some evidence for differences in mood symptoms from controls, but these differences were smaller in magnitude and less consistent in pattern/direction than those observed for males, in accordance with the idea that female deletion carriers exhibit milder phenotypes than male deletion carriers.

Given data suggesting increased rates of $\mathrm{ADHD}^{3} 910$ and inattention in male ${ }^{12}$ and female ${ }^{6}$ deletion carriers, and attentional abnormalities in STS-deficient mice, ${ }^{17}$ we anticipated group differences on attentionally demanding cognitive tasks. Although we did find some evidence that male deletion carriers exhibited slower reaction times than male controls on a simple stimulus-response task (consistent with impaired attention, reduced motor impulsivity and/or slower processing speed), the two groups did not differ on the Trail Making Tasks. This lack of effect could be explained by low power. We did find evidence across both male and female deletion groups for poorer performance on the Fluid Intelligence Task, taxing multiple high-level cognitive skills; this performance deficit did not translate into impairments in academic performance.

We examined, for the first time, the effects of XLI-associated genetic mutations on neuroanatomy, although only in female carriers. Our analyses provide preliminary evidence for reduced right putamen and pallidum volume, and left accumbens volume, but no other subcortical structural changes, in deletion carriers relative to controls. We argue that these specific structural differences are genuine, and could partially explain effects on disorder risk/cognition/behaviour: a) STS is highly expressed in the basal ganglia during human neurodevelopment ${ }^{8}$ and adult STS-deficient male mice exhibit substantially altered striatal neurochemistry, ${ }^{47}$ b) reduced volume of the putamen/nucleus accumbens is observed in idiopathic autism ${ }^{48}$ and ADHD $^{49}$ cases (with reduced pallidum volume also seen in the former), c) adult basal ganglia volumes correlate with aspects of intelligence ${ }^{50}$ and this structure mediates attention/distractibility. ${ }^{51}$ Future functional neuroimaging studies in male and female deletion carriers might examine the extent to which the structure, function and neurochemistry of the basal ganglia correlates with behavioural and cognitive measures. As basal ganglia serotonergic (5-HT) function mediates attention, impulsivity and mood phenotypes (notably via $5-\mathrm{HT}_{2 \mathrm{~A}}$ and $5-\mathrm{HT}_{2 \mathrm{C}}$ receptors $)^{52} 53$ and is altered in STS-deficient mice, ${ }^{4 A}$ a particular focus on this system may be warranted.

In summary, this study has highlighted a novel medical phenotype coupled with XLI-associated mutations, has confirmed an excess of depression and anxiety-related traits in male carriers, and has, for the first time, identified cognitive and neuroanatomical correlates of these genetic differences. Our findings indicate that individuals with XLI might benefit from multidisciplinary clinical care from dermatologists, psychiatrists, and cardiologists, and should lead to improved genetic counselling for patients and their families.

Correction notice This article has been corrected since it was published Online First. A minor error in reporting the number of female control subjects in the main text has been corrected. The error does not change any of the analyses or conclusions of the paper

Twitter Jack FG Underwood @JFGUnderwood, Kimberley M Kendall @DrKKendall, George Kirov@GeorgeKirov1 and William Davies @DrWillDavies77

Acknowledgements This research has been conducted using the UK Biobank resource under Application Numbers 14421 and 17044.

Contributors LB, KMK and XC analysed the data; JFGU and GK called the CNVs; WD conceived the project, drafted the manuscript and took part in all analysis steps; all authors edited the draft manuscript. WD is responsible for the overall content of the manuscript.

Funding LB was funded by the Cardiff University School of Psychology Research Internship (SPRInt) Programme. JFGU was funded by a Wellcome Trust GW4CAT Clinical Research Fellowship and is supported via Welsh Clinical Academic Track funded by Health Education and Improvement Wales. KMK was funded by a Wellcome Trust Clinical Research Fellowship (201171/Z/16/Z). The work was conducted within the Medical Research Council Centre for Neuropsychiatric Genetics and Genomics (Centre Grant Number MR/L010305/1).

Disclaimer The funders played no role in study design, data collection, data analysis, manuscript preparation and/or publication decisions.

\section{Competing interests None declared.}

\section{Patient consent for publication Not required.}

Ethics approval Ethical approval for the study was granted by the North West multicentre ethics committee, UK under Research Ethics Committee approval number 11/NW/0382.

Provenance and peer review Not commissioned; externally peer reviewed.

Data availability statement Data may be obtained from a third party and are not publicly available. All CNV calls will be made available to the UK Biobank, in accordance with their requirements. Genetic and phenotypic data may be accessed through application to the UK Biobank (https://www.ukbiobank.ac.uk/).

Open access This is an open access article distributed in accordance with the Creative Commons Attribution 4.0 Unported (CC BY 4.0) license, which permits others to copy, redistribute, remix, transform and build upon this work for any purpose, provided the original work is properly cited, a link to the licence is given, and indication of whether changes were made. See: https://creativecommons.org/ licenses/by/4.0/.

\section{ORCID iDs}

Lucija Brcic http://orcid.org/0000-0002-8115-3644

Jack FG Underwood http://orcid.org/0000-0003-1731-6039

Kimberley M Kendall http://orcid.org/0000-0002-6755-6121

Xavier Caseras http://orcid.org/0000-0002-8490-6891

George Kirov http://orcid.org/0000-0002-3427-3950

William Davies http://orcid.org/0000-0002-7714-2440

\section{REFERENCES}

1 Fernandes NF, Janniger CK, Schwartz RA. X-Linked ichthyosis: an oculocutaneous genodermatosis. J Am Acad Dermatol 2010;62:480-5.

2 Takeichi T, Akiyama M. Inherited ichthyosis: non-syndromic forms. J Dermatol 2016;43:242-51

3 Kent L, Emerton J, Bhadravathi V, Weisblatt E, Pasco G, Willatt LR, McMahon R, Yates JRW, ichthyosis X-linked. X-Linked ichthyosis (steroid sulfatase deficiency) is associated with increased risk of attention deficit hyperactivity disorder, autism and social communication deficits. J Med Genet 2008:45:519-24.

4 Cuevas-Covarrubias SA, Valdes-Flores M, Orozco Orozco E, Díaz-Zagoya JC, KofmanAlfaro SH. Most "sporadic" cases of X-linked ichthyosis are not de novo mutations. Acta Derm Venereol 1999;79:143-4.

5 Lykkesfeldt G, Lykkesfeldt A, Høyer H, Skakkebaek NE. Steroid sulphatase deficiency associated with testis cancer. The Lancet 1983;322.

6 Cavenagh A, Chatterjee S, Davies W. Behavioural and psychiatric phenotypes in female carriers of genetic mutations associated with X-linked ichthyosis. PLoS One 2019:14: 0212330

7 Perumal AS, Robins E. Regional and subcellular distribution of aryl- and steroid sulfatases in brain. Brain Res 1973;59:349-58. 
8 Stergiakouli E, Langley K, Williams H, Walters J, Williams NM, Suren S, Giegling I, Wilkinson LS, Owen MJ, O'Donovan MC, Rujescu D, Thapar A, Davies W. Steroid sulfatase is a potential modifier of cognition in attention deficit hyperactivity disorder. Genes Brain Behav 2011:10:334-44.

9 Diociaiuti A, Angioni A, Pisaneschi E, Alesi V, Zambruno G, Novelli A, El Hachem M. XLinked ichthyosis: clinical and molecular findings in 35 Italian patients. Exp Dermatol 2019;28:1156-1163.

10 Rodrigo-Nicolás B, Bueno-Martínez E, Martín-Santiago A, Cañueto J, Vicente A, Torrelo A, Noguera-Morel L, Duat-Rodríguez A, Jorge-Finnigan C, Palacios-Álvarez I, GarcíaHernández JL, Sebaratnam DF, González-Sarmiento R, Hernández-Martín A. Evidence of the high prevalence of neurological disorders in nonsyndromic $X$-linked recessive ichthyosis: a retrospective case series. Br J Dermatol 2018;179:933-9.

11 Malik A, Amer AB, Salama M, Haddad B, Alrifai MT, Balwi MA, Davies W, Eyaid W. $X$-Linked ichthyosis associated with psychosis and behavioral abnormalities: a case report. J Med Case Rep 2017;11:267.

12 Chatterjee S, Humby T, Davies W. Behavioural and psychiatric phenotypes in men and boys with $\mathrm{X}$-linked ichthyosis: evidence from a worldwide online survey. PLoS One 2016;11:e0164417.

13 Humby T, Cross ES, Messer L, Guerrero S, Davies W. A pharmacological mouse model suggests a novel risk pathway for postpartum psychosis. Psychoneuroendocrinology 2016;74:363-70.

14 Davies W, Humby T, Trent S, Eddy JB, Ojarikre OA, Wilkinson LS. Genetic and pharmacological modulation of the steroid sulfatase axis improves response control; comparison with drugs used in ADHD. Neuropsychopharmacology 2014;39:2622-32.

15 Trent S, Dean R, Veit B, Cassano T, Bedse G, Ojarikre OA, Humby T, Davies W. Biological mechanisms associated with increased perseveration and hyperactivity in a genetic mouse model of neurodevelopmental disorder. Psychoneuroendocrinology 2013:38:1370-80.

16 Trent S, Dennehy A, Richardson H, Ojarikre OA, Burgoyne PS, Humby T, Davies W. Steroid sulfatase-deficient mice exhibit endophenotypes relevant to attention deficit hyperactivity disorder. Psychoneuroendocrinology 2012;37:221-9.

17 Davies W, Humby T, Kong W, Otter T, Burgoyne PS, Wilkinson LS. Converging pharmacological and genetic evidence indicates a role for steroid sulfatase in attention. Biol Psychiatry 2009;66:360-7.

18 Conroy M, Sellors J, Effingham M, Littlejohns TJ, Boultwood C, Gillions L, Sudlow CLM, Collins R, Allen NE. The advantages of Biobank's open-access strategy for health research. J Intern Med 2019:286:389-97.

19. Uk Biobank website. Available: www.ukbiobank.ac.uk [Accessed 4 Oct 2019].

20 . Affymetrix power tools software. Available: www.affymetrix.com/estore/partners programs/programs/developer/tools/powertool s.affx [Accessed 4 Oct 2019].

21 Wang K, Li M, Hadley D, Liu R, Glessner J, Grant SFA, Hakonarson H, Bucan M. PennCNV: an integrated hidden Markov model designed for high-resolution copy number variation detection in whole-genome SNP genotyping data. Genome Res 2007:17:1665-74

22 World Health Organisation. ICD-10 : International Statistical Classification of Diseases and Related Health Problems. 10th edn. France, 2016.

23 . Mental health questionnaire for UKB web-based questionnaire. Available: http:// www.ukbiobank.ac.uk/wp-content/uploads/2017/09/MentalHealthQuestionnaire_ for_Website-1.pdf [Accessed 16 Dec 2019].

24 Kendall KM, Rees E, Escott-Price V, Einon M, Thomas R, Hewitt J, O'Donovan MC, Owen MJ, Walters JTR, Kirov G. Cognitive performance among carriers of pathogenic copy number variants: analysis of 152,000 UK Biobank subjects. Biol Psychiatry 2017:82:103-10.

25 . Uk Biobank Touchscreen fluid intelligence test. Available: http://biobank.ndph.ox.ac uk/showcase/showcase/docs/Fluidintelligence.pdf [Accessed 16 Dec 2019].

26 Alfaro-Almagro F, Jenkinson M, Bangerter NK, Andersson JLR, Griffanti L, Douaud G, Sotiropoulos SN, Jbabdi S, Hernandez-Fernandez M, Vallee E, Vidaurre D, Webster M, McCarthy P, Rorden C, Daducci A, Alexander DC, Zhang H, Dragonu I, Matthews PM, Miller KL, Smith SM. Image processing and quality control for the first 10,000 brain imaging datasets from UK Biobank. Neuroimage 2018;166:400-24.

27 . FreeSurfer software suite. Available: https://surfer.nmr.mgh.harvard.edu [Accessed 4 Oct 2019].

28 Hoaglin DC, Iglewicz B, Tukey JW. Performance of some resistant rules for outlier labeling. J Am Stat Assoc 1986;81:991-9.

29 Lenhard W, Lenhard A. Calculation of effect sizes. Available: https://www. psychchometrica.de/effect_size.html [Accessed 12 Sep 2019].

30 Benjamini Y, Hochberg Y. Controlling the false discovery rate: a practical and powerful approach to multiple testing. Journal of the Royal Statistical Society: Series B 1995; 57:289-300

31 Trent S, Cognitive DW. Cognitive, behavioural and psychiatric phenotypes associated with steroid sulfatase deficiency. WJTM 2013;2:1-12

32 Craig WY, Roberson M, Palomaki GE, Shackleton CHL, Marcos J, Haddow JE. Prevalence of steroid sulfatase deficiency in California according to race and ethnicity. Prenat Diagn 2010;30:893-8.

33 Langlois S, Armstrong L, Gall K, Hulait G, Livingston J, Nelson T, Power P, Pugash D, Siciliano D, Steinraths M, Mattman A. Steroid sulfatase deficiency and contiguous gene deletion syndrome amongst pregnant patients with low serum unconjugated estriols. Prenat Diagn 2009;29:966-74
34 Fry A, Littlejohns TJ, Sudlow C, Doherty N, Adamska L, Sprosen T, Collins R, Allen $\mathrm{NE}$, Sociodemographic Cof. Comparison of sociodemographic and health-related characteristics of UK Biobank participants with those of the general population. Am J Epidemio/ 2017:186:1026-34.

35 Hand JL, Runke CK, Hodge JC. The phenotype spectrum of X-linked ichthyosis identified by chromosomal microarray. J Am Acad Dermatol 2015;72:617-27.

36 Zoni-Berisso M, Lercari F, Carazza T, Domenicucci S. Epidemiology of atrial fibrillation: European perspective. Clin Epidemiol 2014;6:213-20.

37 Delfino M, Procaccini EM, Illiano GM, Milone A. X-Linked ichthyosis: relation between cholesterol sulphate, dehydroepiandrosterone sulphate and patient's age. $\mathrm{Br}$ J Dermatol 1998;138:655-7.

38 Idkowiak J, Taylor AE, Subtil S, O'Neil DM, Vijzelaar R, Dias RP, Amin R, Barrett TG, Shackleton CHL, Kirk JMW, Moss C, Arlt W. Steroid sulfatase deficiency and androgen activation before and after puberty. J Clin Endocrinol Metab 2016;101:2545-53.

39 Magnani JW, Moser CB, Murabito JM, Sullivan LM, Wang N, Ellinor PT, Vasan RS, Benjamin EJ, Coviello AD. Association of sex hormones, aging, and atrial fibrillation in men: the Framingham heart study. Circ Arrhythm Electrophysiol 2014;7:307-12.

40 Krijthe BP, de Jong FH, Hofman A, Franco OH, Witteman JCM, Stricker BHC, Heeringa J. Dehydroepiandrosterone sulfate levels and risk of atrial fibrillation: the Rotterdam study. Eur J Prev Cardiol 2014;21:291-8.

41 Ravaglia G, Forti P, Maioli F, Sacchetti L, Nativio V, Scali CR, Mariani E, Zanardi V, Stefanini A, Macini PL. Dehydroepiandrosterone-sulfate serum levels and common age-related diseases: results from a cross-sectional Italian study of a general elderly population. Exp Gerontol 2002:37:701-12.

42 Maki Y, Takeichi T, Kono M, Tanaka Y, Akiyama M. Case of mild X-linked ichthyosis complicated with paroxysmal supraventricular tachycardia and anemia. J Dermatol 2018;45:e275-6.

43 Trent S, Fry JP, Ojarikre OA, Davies W. Altered brain gene expression but not steroid biochemistry in a genetic mouse model of neurodevelopmental disorder. Mol Autism 2014;5:21.

44 Clemens DJ, Tester DJ, Giudicessi JR, Bos JM, Rohatgi RK, Abrams DJ, Balaji S, Crotti L, Faure J, Napolitano C, Priori SG, Probst V, Rooryck-Thambo C, Roux-Buisson N, Sacher F, Schwartz PJ, Silka MJ, Walsh MA, Ackerman MJ. International triadin knockout syndrome registry. Circ Genom Precis Med 2019;12:e002419.

45 Denham NC, Pearman CM, Caldwell JL, Madders GWP, Eisner DA, Trafford AW, Dibb KM. Calcium in the pathophysiology of atrial fibrillation and heart failure. Front Physiol 2018;9:1380.

46 Nicolas LB, Pinoteau W, Papot S, Routier S, Guillaumet G, Mortaud S. Aggressive behavior induced by the steroid sulfatase inhibitor COUMATE and by DHEAS in CBA/H mice. Brain Res 2001;922:216-22.

47 Trent S, Cassano T, Bedse G, Ojarikre OA, Humby T, Davies W. Altered serotonergic function may partially account for behavioral endophenotypes in steroid sulfatasedeficient mice. Neuropsychopharmacology 2012;37:1267-74.

48 van Rooij D, Anagnostou E, Arango C, Auzias G, Behrmann M, Busatto GF, Calderon S, Daly E, Deruelle C, Di Martino A, Dinstein I, Duran FLS, Durston S, Ecker C, Fair D, Fedor J, Fitzgerald J, Freitag CM, Gallagher L, Gori I, Haar S, Hoekstra L, Jahanshad N, Jalbrzikowski M, Janssen J, Lerch J, Luna B, Martinho MM, McGrath J, Muratori F, Murphy CM, Murphy DGM, O'Hearn K, Oranje B, Parellada M, Retico A, Rosa P, Rubia K, Shook D, Taylor M, Thompson PM, Tosetti M, Wallace GL, Zhou F, Buitelaar JK. Cortical and subcortical brain morphometry differences between patients with autism spectrum disorder and healthy individuals across the lifespan: results from the enigma ASD Working group. AJP 2018;175:359-69.

49 Hoogman M, Bralten J, Hibar DP, Mennes M, Zwiers MP, Schweren LSJ, van Hulzen KJE, Medland SE, Shumskaya E, Jahanshad N, Zeeuw Pde, Szekely E, Sudre G, Wolfers T, Onnink AMH, Dammers JT, Mostert JC, Vives-Gilabert Y, Kohls G, Oberwelland E, Seitz J, Schulte-Rüther M, Ambrosino S, Doyle AE, Høvik MF, Dramsdahl M, Tamm L, van Erp TGM, Dale A, Schork A, Conzelmann A, Zierhut K, Baur R, McCarthy H, Yoncheva YN, Cubillo A, Chantiluke K, Mehta MA, Paloyelis Y, Hohmann S, Baumeister S, Bramati I, Mattos P, Tovar-Moll F, Douglas P, Banaschewski T, Brandeis D, Kuntsi J, Asherson P, Rubia K, Kelly C, Martino AD, Milham MP, Castellanos FX, Frodl T, Zentis M, Lesch K-P, Reif A, Pauli P, Jernigan TL, Haavik J, Plessen KJ, Lundervold AJ, Hugdahl K, Seidman LJ, Biederman J, Rommelse N, Heslenfeld DJ, Hartman CA, Hoekstra PJ, Oosterlaan J, Polier Gvon, Konrad K, Vilarroya O, Ramos-Quiroga JA, Soliva JC, Durston S, Buitelaar JK, Faraone SV, Shaw P, Thompson PM, Franke B. Subcortical brain volume differences in participants with attention deficit hyperactivity disorder in children and adults: a cross-sectional mega-analysis. The Lancet Psychiatry 2017:4:310-9.

50 Rhein C, Mühle C, Richter-Schmidinger T, Alexopoulos P, Doerfler A, Kornhuber J. Neuroanatomical correlates of intelligence in healthy young adults: the role of basal ganglia volume. PLoS One 2014;9:e93623.

51 Nakajima M, Schmitt LI, Halassa MM. Prefrontal cortex regulates sensory filtering through a basal Ganglia-to-Thalamus pathway. Neuron 2019;103:445-58.

52 Di Matteo V, Pierucci M, Esposito E, Crescimanno G, Benigno A, Di Giovanni G. Serotonin modulation of the basal ganglia circuitry: therapeutic implication for Parkinson's disease and other motor disorders. Prog Brain Res 2008;172:423-63.

53 Robinson ESJ, Dalley JW, Theobald DEH, Glennon JC, Pezze MA, Murphy ER, Robbins TW. Opposing roles for $5-\mathrm{HT} 2 \mathrm{~A}$ and $5-\mathrm{HT} 2 \mathrm{C}$ receptors in the nucleus accumbens on inhibitory response control in the 5-choice serial reaction time task. Neuropsychopharmacology 2008;33:2398-406. 